not seem to have a carcinogenic effect, but hepatotoxicity is common. Patients should be followed up closely and should have a liver biopsy after a total dose of $1.5 \mathrm{~g}$ - that is, after one to two years of low dose treatment.

Unfortunately the trials we have mentioned are difficult to assess as inhaled steroids were either not given at all or given in uncertain amounts. There is clearly a need for an alternative treatment to systemic steroids in this group of patients. The treatment should be less toxic and at least as efficacious. In any trials of new drugs optimal doses of bronchodilators and inhaled steroids should be rigidly defined, and it is important to know whether the drug is effective in its own right or only as a "steroid sparing agent."

R J SHINER Visiting Consultant Physician

D M GEDDES

Brompton Hospital,

Consultant Physician

London SW3 6HP

1 Adinoff AD, Hollister JR. Steroid-induced fractures and bone loss in patients with asthma N Engl f Med 1983;309:265-8.

2 Horn CR, Cochrane GM. Management of asthma in general practice. Respiratory Medicine 1989;83:67-70.

British Thoracic and Tuberculosis Asseciation. A controlled trial of inhaled corticosteroids in patients receiving prednisolone tablets for asthma. Br $\mathcal{F}$ Dis Chest 1976;70:95-103.

4 Brompton/Medical Research Council Collaborative Trial. Double blind trial comparing two dosage schedules of heclomethasone dipropionate aerosol in the treatment of chronic bronchial asthma. Lancet 1974;ii:303-7.

5 Zeiger RS, Schatz M, Sperling W, Simon RA, Stevenson DD. Efficacy of troleandomycin in out patients with severe corticosteroid-dependent asthma. F Allergy Clin Immunol 1980;66:438-46.

6 Ticktin HE, Zimmerman HJ. Hepatic dysfunction and jaundice in patients receiving iriacetyloleandomycin. N Engl Mepatic dysfunction

7 Wald JA, Friedman BF, Farr RS. An improved protocol for the use of troleandomycin in the treatment of steroid-requiring asthma. I Allergy Clin Immunol 1986;78:36-43.

treatment of steroid-requiring asthma. $\mathcal{F}$ Allergy Clin Immunol 1986;78:36-43.
Bernstein EI, Bernstein IL, Bodenheimer SS, Pietruski RG. An open study of auranofin in the treatment of steroid dependent asthma. F Allergy Clin Immunol 1988;81:6-16.

9 Hodges NG, Brewis RAL, Howell JBL. An evaluation of azathioprine in severe chronic asthma. Thorax 1971;26:734-9.

10 Mullarkey MF, Blumenstien BA, Andrade WP, Bailey GA, Olason I, Wetzel CE. Methotrexate in the treatment of corticosteroid-dependent asthma. $N$ Eingl f Med 1988;318:603-7.

\section{Serious gaps in response to Griffiths}

\section{Local authorities given the lead: no provision for central direction}

The vacuum created by the government's 16 month silence over the Griffiths report on community care was naturally filled with speculation, rumour, and gossip. Policy discussions lurched back and forth over old ground about which agency should take lead responsibility. Finally, the government has taken a courageous decision, which would have been unthinkable a year ago, to implement the most controversial of Griffiths's proposals and give local authority social services departments the lead responsibility for community care. Their job will be to assess the needs in their localities, set local priorities and service objectives, and arrange the care required by designing, organising, and purchasing it. To allow them to do this effectively social security benefits and existing funds for community care are to be channelled through the single gateway of local authority social services. This money will also be available to support patients at home. If this is adequately funded it will be the first major government initiative to foster care at home, usually the first choice of patients and their families. It will also address the government's concern over the escalating social security bill for residential care, which has now risen to $£ 1$ billion annually.

There are, however, serious gaps in the government's response, which need to be addressed in detail in the white paper promised for the autumn. Griffiths wanted much more decisive central government action to set clear objectives and priorities. He wanted the allocation of resources to social services to be linked with developing nationally agreed plans, and he proposed that there should be tight financial control to ensure that local authorities could not siphon off funds allocated for community care to other more attractive causes. A minister for community care was proposed. There was no such central direction contained in the health minister's speech to parliament last week, and as yet no mechanisms have been devised by which the government can ensure that local planning and implementation are consistent with national priorities. The Social Services Inspectorate has no teeth, and its recommendations are often ignored. If the inspectorate is to monitor these plans then it needs wider powers.

A crucial part of Griffiths's report was the support of the concept of "care management" by which budget holding managers are given responsibility to ensure that an appropriate "package" of services is delivered to a group of clients. Without some fundamental reorganisation of the management of social services and a cultural and attitudinal change in local authorities, shifting money from the social security purse into social services will have little impact on consumers and their families on the receiving end of community care.

The proposals have the potential for righting the current gross geographical imbalance of services-but only if resources available to authorities match the local costs of domiciliary and residential care. At present prosperous areas with a plentiful supply of houses for conversion for residential care are paradoxically often the cheapest areas in which to provide care. Social security benefits pour into suburban and rural retirement areas leaving inner city dwellers unable to pay for the cost of a local residential or nursing home place within benefit levels. The allocation of resources to authorities must be linked not only to social need in terms of the prevalence of disability and the demographic pattern of handicap and mental illness but also to the local cost of delivering that care. Current patterns of allocating social security benefit are distorted by local availability of residential care. The revenue funding of the white paper Working for Patients recognises the fundamental principle that geographical accident should not disadvantage patients from access to good local care. The same principle must be embodied in the white paper on community care.

The impact on the health service may be surprisingly slight. The response falls back on "the discredited refuge of exhortation to joint planning" between health and social services. Griffiths's nice turn of phrase warned the government against doing this, emphasising that there must be incentives to both authorities to engage in such activity. There is no such incentive mentioned in the response. I see no incentive either for social services to take on the responsibility for the care of patients in hospitals who no longer need the medical care provided in short stay wards but require extensive domiciliary support or residential care. Between 1986 and 1989, 15\% of all the short stay hospital beds in my own health district were occupied by disabled people who stayed over 90 days and who were waiting for a residential place to be found. The quality of life for these people marooned on a short stay ward is poor, and it is a waste of short stay beds. If the government is serious about community care it must not neglect those patients who are trapped down an NHS cul de sac.

There is no mention in the government's response of releasing resources from the health service's existing provision for long stay care and transferring this resource to social services. Unless this is done we shall continue to have parallel services developing in the health service and local authorities, 
and the current haphazard uncoordinated development of community care will continue.

The proposals for care of mentally ill people are clearly an afterthought, a rapidly created and clever solution to the problem that local authorities have been reluctant to take on their responsibilities to care for mentally ill people. $\mathrm{Mr}$ Freeman outlined further plans to parliament the day after Mr Clarke's speech. The responsibility for assessing and organising care will be with local authorities, as for other care groups, but health authorities will control the grant and care plans will need to be approved before patients leave hospital. This should go some way to satisfying the psychiatric lobby pressing for health authority control.

The most welcome part of Mr Freeman's speech was the clear commitment to continue with the policy of closure of the large institutions but in a more controlled fashion. He has not bowed to the reactionary voices raised both in parliament and by some campaigners who wished to reverse the policy on the basis of a misguided idea that this would remove the problem of homeless, drifting, mentally disordered people. The disasters of the past 20 years of unplanned discharges cannot be reversed by bolting the stable door now. Especially welcome are the plans to allow unconventional private capital investment in hospital closure programmes, which will enable the right kinds of alternative accommodation to be developed as part of a package. The source of the revenue for double running costs incurred in a closure programme during the run down of a hospital is still not clear.

This is a partial response that could be fleshed out into a workable comprehensive policy. It largely addresses the problems of residential care. So far the government has ensured that it can contain spending on social security, and the Treasury must be well pleased. Now we want to see the details that will produce a well managed, properly coordinated community service, and we want to see such a service adequately funded. There is a great deal more work to be done before we can be enthusiastic about the proposals.

ELAINE MURPHY

District General Manager,

Lewisham and North Southwark Health Authority,

Guy's Hospital,

London SE1

1 Griffiths R. Community care. Agenda for action. London: HMSO, 1988.

\section{A European perspective in regulating clinical research}

\section{Britain needs a national ethical committee}

In the final analysis clinical research has to be self regulating if it is to be properly regulated. Codes, guidelines, committee review, and legal control will not produce a maximum of well conducted research unless they function to stimulate ethically informed behaviour that can be expected from the researchers themselves. Yet it is essential that research proposals are seen to be checked against agreed ethical standards and vetted by those who are not putting forward the proposals. A system of regulation beyond the judgment and conscience of individual researchers is essential if minimum standards are to be maintained in the face of the inexperience, haste, or poor judgment of the few who have brought clinical research into disrepute.

The survey by the Institute of Medical Ethics of the constitution and workings of hospital ethics committees in Britain ${ }^{1}$ and exposures of research malpractice in the $1980 \mathrm{~s}^{23}$ show that our system of public regulation leaves much to be desired. It cannot ensure public confidence in the ethical conduct of research when some of our committees do not insist on the need for our informed consent before all research procedures and are aware of research being undertaken that has not been ethically reviewed. We should not tolerate the vagaries that result from the Department of Health merely requesting health authorities to set up such committees and to adopt model constitutions drawn up by professional bodies. These vagaries culminate in the department being unable to say how many such committees exist, how they are constituted, and where they are located.

A meeting of representatives of European medical research councils in WHO regional offices in Europe earlier this year reinforced these points by showing how much may be learnt from the best European practices (particularly those in Scandinavia) without falling into the step of excessive, minute regulation set by the regulations of the National Institutes of Health in the United States. ${ }^{+}$

Four things are needed. Firstly, ethics committees need official status and recognition when they are set up. Secondly, they need a uniform, core constitution backed by government regulation and guaranteeing active lay participation in their deliberations. Thirdly, they need an optimal workload to encourage experience of ethical review to be built up within them. Fourthly, some kind of national ethics committee is needed to function not so much as a court of appeal in individual proposals but more as the source of guidance on general principles and of some measure of uniformity of practice in relation to particularly contentious decisions.

A national committee for research ethics could in Britain be combined with a national body for guidance on medical ethics in general (as is the case in France). Its potential usefulness is shown when we consider the following questions: How are local committees to decide on the principle (maintained by some) that randomised trials do not require full informed consent from patients enrolled into cohorts receiving standard treatment in a comprehensive study? Are we to tolerate randomised controlled trials being treated as a justified exception to the consent rule in one part of the country but not in another? If we need a central body to oversee and report on the ethics committee in clinics for in vitro fertilisation why do we not need one for establishments conducting research outside embryology?

Above all we need an exchange of ideas and the harmonising of practices among European nations. These are demanded by the international nature of much research, the possibility of contentious research projects being carried out in places where control is most lax, and the fundamental need to learn from each other's successes and failures.

PETER BYRNE

Lecturer in Philosophy of Religion,

Centre of Medical Law and Ethics,

King's College,

London WC2R 2LS

1 Nicholson RH, ed. Medical research with children. Oxford: Oxford University Press, 1986.

2 Faulder C. Whose body is it? London: Virago, 1985.

3 Byrne P. Medical research and the human subject: problems of consent and control in the UK experience. Ann N Y'Acad Sci 1988;530:144-53.

4 Levine RJ. Ethics and the regulation of clinical research. 2nd ed. Baltimore and Munich: Urban and Schwarzenburg, 1986. 